\title{
TEXTURE OF COLD-ROLLED $\beta$-TITANIUM ALLOYS WITH ADDITIONS OF HYDROGEN
}

\author{
T.A. SOKOLOVA ${ }^{\mathrm{a}, *}$, L.I. ANISIMOVA ${ }^{\mathrm{a}}$ and B.K. SOKOLOV ${ }^{\mathrm{b}}$ \\ ${ }^{\mathrm{a}}$ Institute of Machines Science, ${ }^{\mathrm{b}}$ Institute of Metals Physics, \\ Ural Division, Russian Academy of Sciences, Ekaterinburg, Russia
}

(Received in final form 28 September 1997)

This paper presents a study of texture investigations in a cold-rolled VT-35 titanium alloy with hydrogen concentration varied within $0.04-0.55 \mathrm{wt} . \%$. It is shown that the character of the rolling texture depends on hydrogen contents and is caused by changes in the mechanism of plastic deformation of the alloy. The poorly deformable alloy may be plastified by introducing small additions of hydrogen $(0.06-0.12 \mathrm{wt} . \%)$. The texture formed in this case has a relatively strong $\{112\}-\{100\}\langle 110\rangle$ component and a lowintense $\{111\}$ component.

Keywords: Texture; Cold-rolling; Hydrogen; Plastic deformation; Titanium alloy

\section{INTRODUCTION}

The problem of hydrogen effect on the behavior of metallic materials upon deformation has attracted attention of researchers for many years. For $\alpha-\mathrm{Fe}$ and $\mathrm{Ti}$ alloys it was noted that in some cases the addition of hydrogen increased the plasticity during tensile tests. There are some hypotheses connecting the plastifying effect of hydrogen with the hydrogen-dislocation interaction during the plastic deformation (Kimura and Matsui, 1987; Il'in, 1994).

\footnotetext{
* Corresponding author. Institute of Engineering Sciences, Russian Academy of Sciences, Pervomaiskaya Street 91, 620219 Ekaterinburg, Russia.
} 
It is known that texture formation during plastic deformation is determined by the operating mechanisms of metal forming. This study of the processes of texture formation in a hydrogen-containing stable BCC-titanium alloy was aimed at obtaining data on the effect of hydrogen on the mechanism of plastic deformation by cold-rolling and revealing of new possibilities of controlling the texture.

\section{EXPERIMENTAL}

Sheets of commercial VT-35 alloy in thickness of $1.2 \mathrm{~mm}$ of the following composition (wt.\%) were used: $2.7 \mathrm{Al}, 15.2 \mathrm{~V}, 3.0 \mathrm{Cr}, 2.8 \mathrm{Sn}$, $0.55 \mathrm{Mo}$ and $0.4 \mathrm{Zr}$ (Ti for balance).

Sheet samples were annealed in a vacuum of $1.33 \times 10^{2} \mathrm{~Pa}$ at $850^{\circ} \mathrm{C}$ for $2 \mathrm{~h}$, following which they were hydrogenized after Siverts' law $\left(S=k p^{1 / 2}\right)$. The hydride of titanium $\left(\mathrm{TiH}_{2}\right)$ was used as a source of the hydrogen. The hydrogen concentration in the samples varied within $0.04-0.55 \mathrm{wt} . \%$. Cooling was realized either in air (A-alloy) or after quenching from $700^{\circ} \mathrm{C}$ in icy water (B-alloy).

The alloy was a single-phase $\mathrm{BCC}(\beta)$ solid solution and this state was retained during the subsequent cold-rolling.

The hydrogenized samples were cold-rolled to $30-60 \%$ reductions. The nature of the deformation texture was judged from $\{110\}$ pole figures obtained in the reflection geometry. Quantitative data on the intensity of textures were obtained by pole densities $P_{h k l}$ of the inverse pole figure for $\mathrm{ND}$ (normal direction to the rolling plane), calculated in multiples of the random density (relative units).

\section{RESULTS AND DISCUSSION}

The $\{110\}$ pole figures of samples rolled to $30 \%$ (Fig. 1) show that the texture formed is typical of BCC metals and may be described by the components $\{111\}\langle 110\rangle-\langle 112\rangle,\{112\}\langle 110\rangle$ and $\{001\}\langle 110\rangle$. The strongest component of the texture of the hydrogen-free B-alloy $\left(C_{\mathrm{H}}=0\right)$ is $\{111\}\langle 110\rangle-\langle 112\rangle$.

Small additions of hydrogen to the B-alloy $\left(C_{\mathrm{H}}=0.06-0.116 \mathrm{wt} . \%\right)$ change the character of rolling texture, namely, increase the intensity 


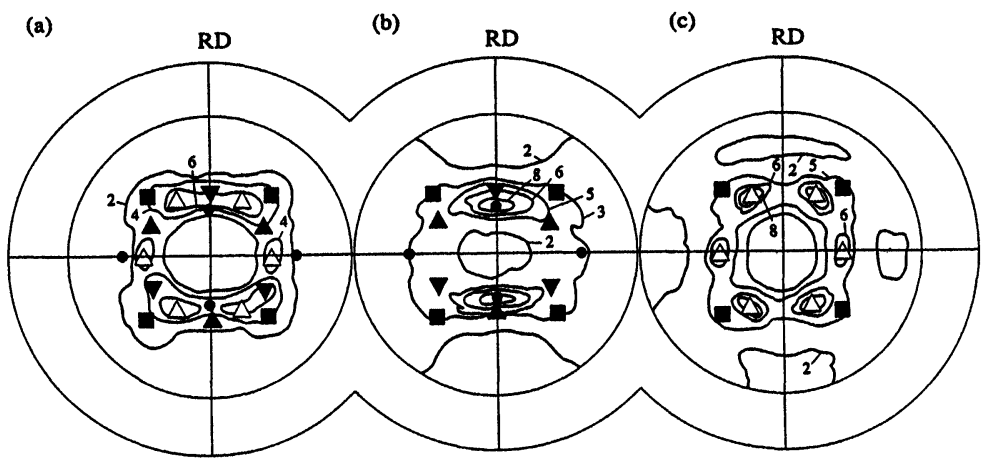

FIGURE $1\{110\}$ pole figures of the cold-rolled VT-35 alloy $(\varepsilon=30 \%)$ with hydrogen concentrations $C_{\mathrm{H}}$ equal to 0 (a), 0.08 (b) and $0.554 \mathrm{wt} \%$ (c): (घ) $-\{001\}\langle 110\rangle$, $(\bullet)-\{111\}\langle 112\rangle,(\Delta)-\{111\}\langle 110\rangle$ and $(\bullet)-\{112\}\langle 110\rangle$ orientations. Intensities are indicated by numbers along the contour lines.

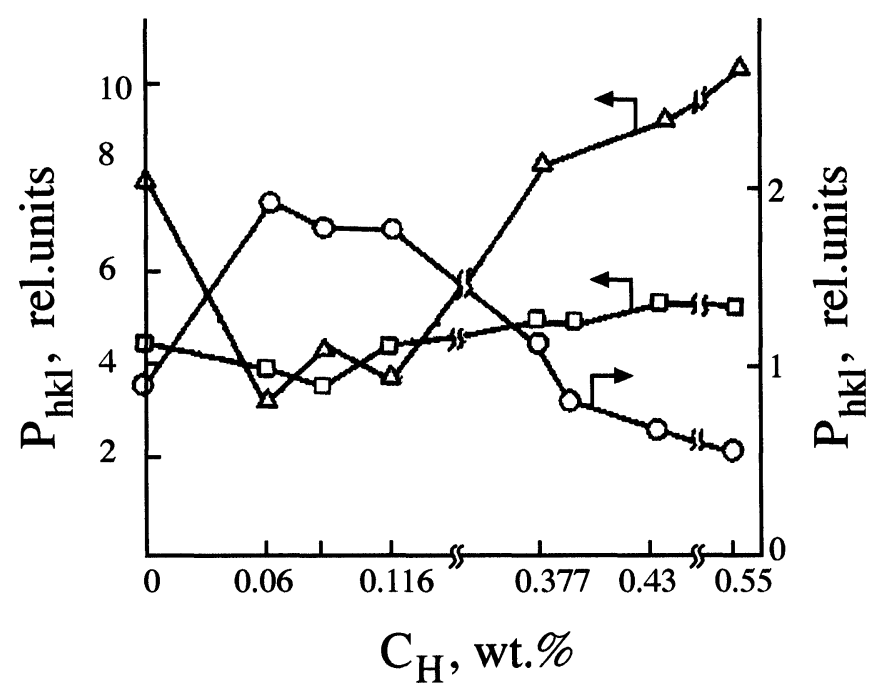

FIGURE 2 Effect of hydrogen on pole densities $P_{h k l}$ of the inverse pole figures taken from the surface of the cold-rolled VT-35 B-alloy: $(\square)-\{001\},(\Delta)-\{111\}$, (O) $-\{112\} . \varepsilon=30 \%$.

of the $\{112\}\langle 110\rangle$ component primarily at the expense of a decrease in the intensity of the $\{111\}\langle 112\rangle-\langle 110\rangle$ component (Fig. 2).

At higher hydrogen concentrations $\left(C_{\mathrm{H}}=0.377 \mathrm{wt} . \%\right)$ the $\{111\}$ component increases again and the $\{112\}$ component decreases. 

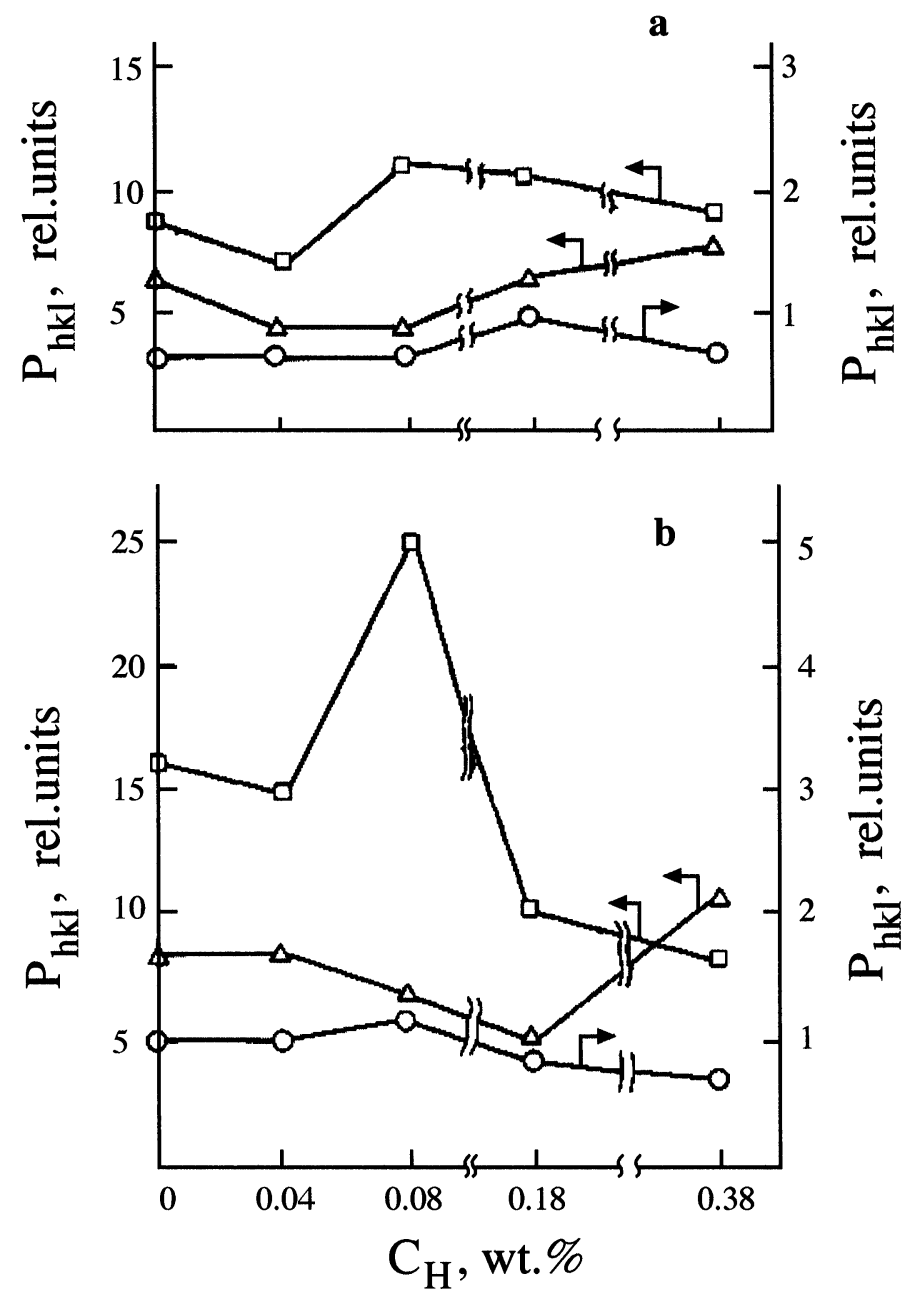

FIGURE 3 Effect of hydrogen on pole densities $P_{h k l}$ of the inverse pole figures taken from the surface of the cold-rolled VT-35 A-alloy $(\square)-\{001\},(\triangle)-\{111\}$, (O) $-\{112\}$. (a) $-\varepsilon=30 \%$, (b) $-\varepsilon=60 \%$.

The texture being formed is virtually identical to that of the hydrogenfree alloy.

An increase in hydrogen content to $C_{\mathrm{H}}=0.43-0.55 \mathrm{wt} . \%$ causes even greater growth of the $\{111\}$ component and a decrease in the intensity of the $\{112\}\langle 110\rangle$ component. 
The strongest component of the texture of the hydrogen-free A-alloy $\left(C_{\mathrm{H}}=0\right)$ is $\{001\}\langle 110\rangle$.

Small additions of hydrogen to the alloy $\left(C_{\mathrm{H}}=0.04-0.08 \mathrm{wt} . \%\right)$ increase the intensity of $\{001\}\langle 110\rangle$ component, which decreases in rolling texture at higher hydrogen concentrations $\left(C_{\mathrm{H}}=0.38 \mathrm{wt} . \%\right)$ (Fig. 3(a)).

The described texture changes take place in the A- and B-alloys with various hydrogen contents after their cold-rolling to a reduction of $60 \%$ (Fig. 3(b)).

The degree of alloying with hydrogen also determines the specific features of the structure formed upon deformation. Our investigations show that the microstructure of cold-rolled hydrogen-free alloys contains mechanical twins along with slip bands, which indicates that two processes are involved in the deformation: slipping and twinning.

Small additions of hydrogen $\left(C_{\mathrm{H}}=0.06-0.116 \mathrm{wt} . \%\right)$ change the deformation structure, which in this case consists of slip bands of various system without twins.

Hydrogen concentrations $C_{\mathrm{H}}>0.18 \mathrm{wt} . \%$ again activate the process of twinning. At $C_{\mathbf{H}}=0.38 \mathrm{wt} . \%$ the amount of twins becomes the most important feature of the structure and the intensity of the $\{111\}$ component in the texture of these samples is the highest (Fig. 2).

As the results of the investigation show, the poorly deformable alloy VT-35 may be plastified by introducing small amounts of hydrogen. In this case the simultaneously acting processes of slipping and twinning are replaced by deformation via facilitated slip. The texture formed in this case may be described by the relatively high value of the texture coefficient, determining the ratio of the pole densities $P_{h k l}$ of the inverse pole figures for ND: $K=\left(P_{112}+P_{100}\right) / P_{111}$.

This coefficient may serve as an indicator of the plastifying effect of hydrogen during cold-rolling of stable $\beta$-Ti alloys. The magnitude of $K$ may vary in certain limits depending on the initial textural state of the alloy before deformation as well as on technological parameters of rolling.

\section{CONCLUSION}

The results of this research indicate that small additions of hydrogen to $\beta$-Ti alloys may cause a plastifying effect upon cold-rolling, which leads 
to the development of strong deformation components $\{112\}-\{100\}$ $\langle 110\rangle$ in their texture. In this case plastic deformation of the alloy mainly occurs by multiple glide and the role of twinning is rather small.

\section{References}

Il'in, A.A. (1994). Mechanism and Kinetics of Phase and Structural Transformations in Titanium Alloys. Moscow: Nauka, 312p.

Kimura, H. and Matsui, H. (1987). Mechanism of hydrogen induced softening and hardening in iron. Scr. Metall., 21, 319-324. 